\title{
Comparative anatomy of pectoral girdle and pectoral fin in Russian sturgeon and American paddlefish
}

\author{
K. Grom ${ }^{1}$, E. Pasicka ${ }^{2}$, K. Tarnawski ${ }^{3}$ \\ ${ }^{1}$ Department of Animal Anatomy, National University of Life and Environmental Sciences of Ukraine, Kiev, Ukraine \\ 2Division of Animal Anatomy, Department of Biostructure and Animal Physiology, Faculty of Veterinary Medicine, \\ Wrocław University of Environmental and Life Sciences, Wroclaw, Poland \\ ${ }^{3}$ Environmental Engineering Institute, Wrocław University of Environmental and Life Sciences, Wroclaw, Poland
}

[Received: 31 May 2015; Accepted: 11 August 2015]

\begin{abstract}
Acipenseriformes occupy an important place in the evolutionary history. Skeleton of their pectoral fins has elements related to teleosts, but also to tetrapods. This article summarises and compares anatomical structure of the pectoral girdle and pectoral fin of Russian sturgeon (Acipenser gueldenstaedtii) and American paddlefish (Polyodon spathula). These species possess pectoral fins with some distinctive features in their structure. The pectoral girdles are composed of both cartilaginous and ossified elements. Unlike sturgeons, American paddlefish does not have an interclavicle and suprascapular cartilage. Moreover, its cleithrum doesn't form medially directed lamina. The quantity of the proximal radials in the investigated fish species are not the same. The dorsal and ventral muscles, which act on the pectoral fin of Russian sturgeon and American paddlefish, are not equally developed. In our opinion, this is caused by the differences in the mode of life, motility of fins, as well as by stabilisation of body during swimming. (Folia Morphol 2016; 75, 2: 173-178)
\end{abstract}

Key words: acipenseriformes, evolution, fish, morphology, skeleton

\section{INTRODUCTION}

Acipenseriformes is a very distinctive and ancient group dated to early Jurassic. This order includes most of the living fossils (sturgeons and paddlefishes) that belong to the lower actinopterygians, and it is represented by two families: Acipenseridae that has 25 extant species, and Polyodontidae that includes only 2 extant species $[1,3,10,11]$. That is why this group is ideal for study and comparison of different evolutional adaptations, namely structure and function of the pectoral fins.

The pectoral fins are believed to be homologous and predecessors of forelimbs in higher vertebrates [20].
Moreover, the fin to limb transition first began in the pectoral fins [6]. On the other hand, teleosts and tetrapods may share no homologous skeletal elements in their forelimbs. The teleost fin has propterygial and mesopterygial elements, but the tetrapod limb is comprised of only a metapterygium. In extant sarcopterygian fishes, the endoskeleton of the pectoral fin is also comprised of one component, metapterygium, articulating with monobasal pectoral girdle. However, basal actinopterigians possess the propterygium and metapterygium with the presence of middle mesopterygial radials articulating with polybasal pectoral girdle $[17,21]$. Recently, the polybasal

Address for correspondence: Dr E. Pasicka, Division of Animal Anatomy, Department of Biostructure and Animal Physiology, Faculty of Veterinary Medicine, Wrocław University of Environmental and Life Sciences, ul. Kożuchowska 1/3, 51-631 Wrocław, Poland, e-mail: edyta.pasicka@yahoo.com 


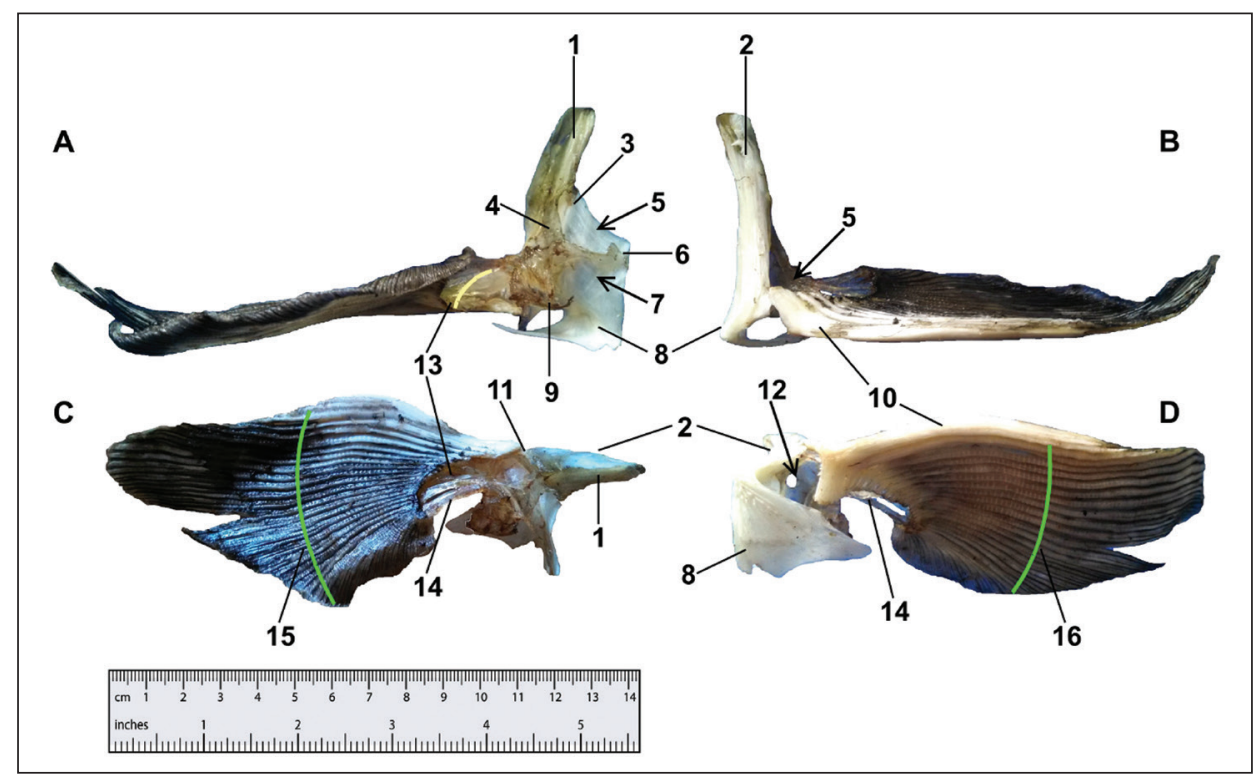

Figure 1. Pectoral girdle and fin structure of Acipenser gueldenstaedtii. A. Posterior view; B. Anterior view; C. Dorsal view; D. Ventral view; 1 - dorsal process of scapula; 2 - cleithrum; 3 - lateral process of scapula; 4 - medial process of scapula; 5 - dorsal muscle canal; 6 - mesocoracoid; 7 - ventral muscle canal; 8 — lamina of cleithrum with propterygial restraining process; 9 — coracoid; 10 — pectoral-fin spine; 11 - propterygium; 12 - foramen of mesocoracoid; 13 - radials; 14 - metapterygium; 15 - dorsal row of lepidotrichia; 16 - ventral row of lepidotrichia.

fin articulation was demonstrated on the preserved fossils of sarcopterygians from the Lower Devonian [23]. In such a case, similarities and differences in Hox patterns during limb development should be reinterpreted accordingly.

Functions of pectoral fins have been well documented in sturgeons [22]. Some recent works were dedicated to the ontogenetic development of the paired fins of sturgeons and paddlefish $[8,9,18]$ and to the expression of Hox genes, in order to describe features of limb developmental regulation $[7,19]$. Still, considerably less attention was paid to the comparative morphology of the pectoral girdle and pectoral fin in Russian sturgeon and American paddlefish.

Thus, the comparative anatomical study of the pectoral girdles and fins of Russian sturgeon and American paddlefish contributes to broadening and spread of the anatomical knowledge that is important for understanding of the evolution process of the paired appendages. Furthermore, it can serve a basis for investigations with the usage of sturgeons and paddlefishes as experimental animals.

\section{MATERIALS AND METHODS}

The study was performed on cadavers of fish that belong to the order Acipenseriformes, namely Russian sturgeon Acipenser gueldenstaedtii Brandt and
Ratzeburg, 1833 and American paddlefish Polyodon spathula Walbaum, 1792. The research material skeletons of the pectoral girdle and muscles that act on the pectoral fin - were provided by the Museum of Animal Anatomy, National University of Life and Environmental Sciences of Ukraine. Specimens were fixed in 10\% neutral buffered formalin with further conducting of anatomical dissection. After skin removal, the muscles that act on the pectoral fin were identified. Then the pectoral girdles with corresponding muscles were removed for further macroscopic investigation of their skeletal elements.

\section{RESULTS}

The pectoral girdle of Russian sturgeon consists of the primary (cartilaginous) and secondary (osseous) parts (Figs. 1, 2).

The cartilaginous part of the shoulder girdle consists of the only one cartilage that has a complex form and no clear division. For convenience, it can be divided into three parts: ventral, elongated forward part - coracoid; dorsal, extended part - scapula; and horizontally placed among them mesocoracoid that connects scapula and coracoid. The suprascapular cartilage is present only in sturgeons, where it attaches to the supracleithrum $[14,18]$. According to Jessen [14], the scapula can be subdivided into dorsal, lateral and medial cartilaginous processes. Together 


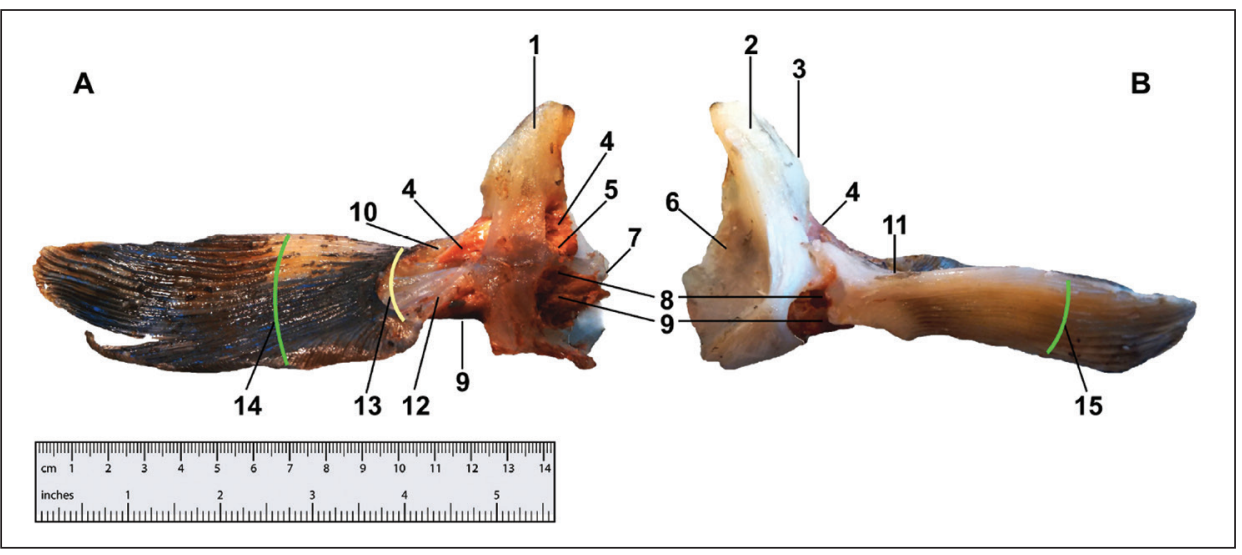

Figure 2. Pectoral girdle, pectoral fin structure and muscles of Acipenser gueldenstaedtii. A. Postero-dorsal view; B. Antero-ventral view; 1 - scapulocoracoid cartilage; 2 - cleithrum; 3 - postcleithrum; 4 - adductor muscle; 5 - dorsal marginal muscle; 6 - lamina of cleithrum; 7 - mesocoracoid; 8 - ventral marginal muscle; 9 - abductor muscle; 10 - propterygium; 11 - pectoral-fin spine; 12 - metapterygium; 13 - radials; 14 - dorsal row of lepidotrichia; 15 - ventral row of lepidotrichia.

with mesocoracoid they surround the dorsal muscle canal. Another classification proposes to consider scapula and coracoid as an entire scapulocoracoid cartilage, and lateral and medial scapula processes as the lateral and medial parts of the mesocoracoid arch $[9,18]$. In the paper herein we will apply Jessen's terminology.

On the ventral surface of the dorsal muscle canal, inside the mesocoracoid, an oval foramen is located into which the vessels and fin nerves from the brachial plexus penetrate. The mesocoracoid, on its posterior surface, has glenoid fossae for attachment to the pectoral fin endoskeletal elements, namely metapterygium, radials and propterygium. The ventral muscle canal is located under the mesocoracoid and is circumscribed by the mesocoracoid, coracoid and lamina of cleithrum. These two large muscle canals serve for penetration of the upper and lower muscle bulks that act on the pectoral fin. The upper muscle complex includes the adductor muscle and the dorsal marginal muscle, while the lower muscle complex - the abductor muscle and the ventral marginal muscle. The adductor and abductor muscles are more developed than marginal muscles. They mainly attach to the proximal ends of the fin rays. In Russian sturgeon, their superficial and profundus parts are not clearly visible. But the dorsal and ventral marginal muscles that mainly act on the pectoral-fin spine allowing erector and depressor movements are well distinguished. According to some scientists, these muscles also serve as protractors and retractors of the pectoral fin ( $m$. protractor pectoralis dorsalis et $m$. retractor pectoralis dorsalis, $m$. protractor pectoralis ventralis et $m$. retractor pectoralis ventralis) [12].

The osseous part of the pectoral girdle is comprised of a clavicle, cleithrum, postcleithrum and supracleithrum. A posttemporal bone is also considered as a part of the shoulder girdle in bony fishes [18]. The early ontogenetic appearance of this bone in sturgeons proves the above statement [15]. The clavicle is a mighty, covering bone located ventrally, and lies medially to the cleithrum. It fuses with the same bone of the opposite side and thus creates a paired structure. Posteriorly and between the clavicles an interclavicle is located. The cleithrum covers anteriorly the middle part of the cartilaginous girdle. It extends medially to form a thin lamina of cleithrum that borders a branchial chamber. The postcleithrum is a wedge-shape bone that is almost fused laterally to the cleithrum. The supracleithrum lies above the postcleithrum and cleithrum. It is attached to the lateral side of the suprascapula cartilage and is overlapped by the posttemporal bone of the skull. Therefore, the supracleithrum connects the pectoral girdle and the skull, and this connection is very rigid in Russian sturgeon.

The endoskeleton of the pectoral fin consists of cartilaginous proximal radials that are unequal in length and wider distally. The short distal radials are situated posteriorly to the proximal radials. The last radial - metapterygium - is the biggest in size and slightly forks on its distal part. The metapterygium and propterygium flank the radials. Together they support the two series of dermal rays, lepidotrichia, 


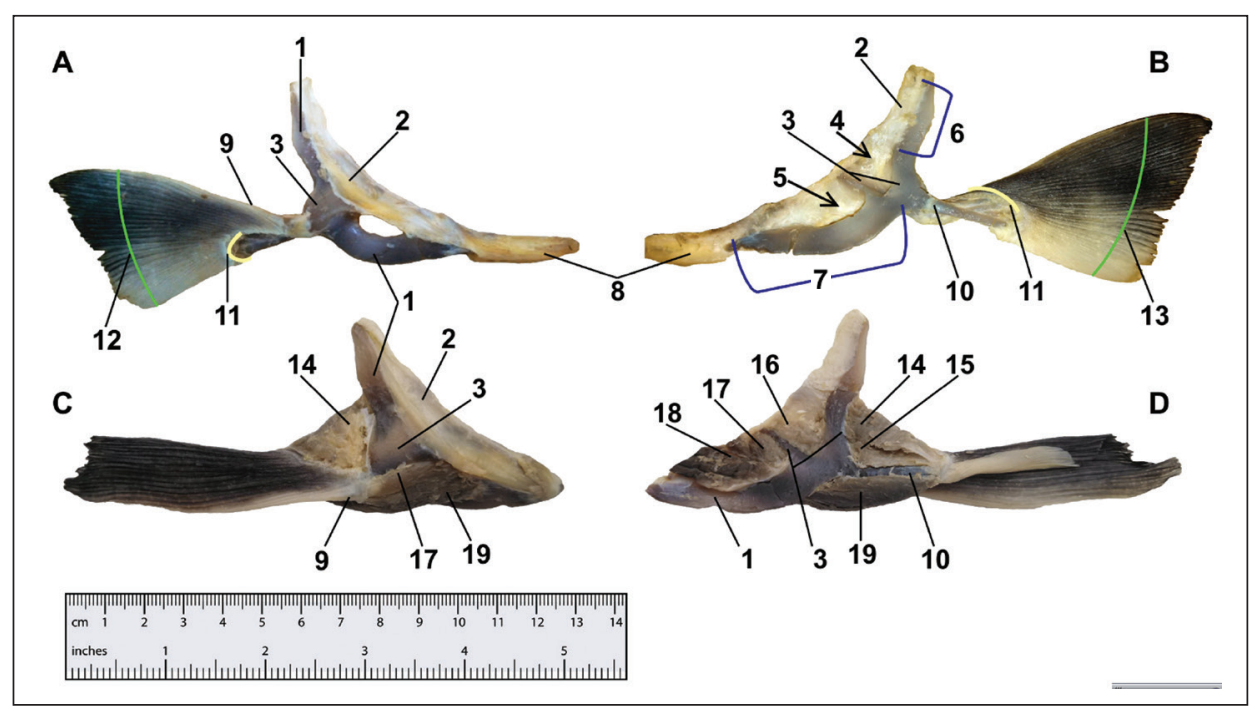

Figure 3. Pectoral girdle, pectoral fin structure and muscles of Polyodon spathula. A, C. Lateral view; B, D. Medial view; 1 - scapulocoracoid; 2 - cleithrum; 3 - mesocoracoid; 4 - dorsal fin muscle canal; 5 - ventral fin muscle canal; 6 - scapular region; 7 - coracoid region; 8 - clavicle; 9 - marginal ray; 10 - metapterygium; 11 - radials; 12 - dorsal row of lepidotrichia; 13 - ventral row of lepidotrichia; 14 — superficial adductor muscle; 15 — deep adductor muscle; 16 — dorsal marginal muscle; 17 — ventral marginal muscle; 18 deep abductor muscle; 19 - superficial abductor muscle.

that comprise the external skeleton of the pectoral fin. Their dorsal and ventral rows are placed opposite to each other and create a space between their proximal ends - the adbasal interlepidotriehial space. Thereby, the lepidotrichia overlap the radials along their distal margins. The distinctive feature of the sturgeons is the presence of a stiff marginal ray - pectoral-fin spine that is characterised by the significant morphological heterogeneity among different sturgeon species $[2,9]$. The pectoral-fin spine is formed by the fusion of the first lepidotrichia of both sides, the quantity of which does not much vary among sturgeon species [9], and equals two fin rays in Russian sturgeon. Therefore, the pectoral-fin spine contributes to the fin robustness. Also, it has an articulated surface for the tight attachment to the propterygium that bears a canal inside for nerves and vessels of the fin [10, 14]. The annual growth increments on the pectoral-fin spine are used to establish the age of the fish [12, 15].

The pectoral girdle of American paddlefish has its own features, compared to that of Russian sturgeon (Fig. 3). Externally it is overlapped by the long and tapered operculum. The endoskeleton of the shoulder girdle is for the most part cartilaginous. It is attached to the inner side of the cleithrum which does not form medially directed lamina. The supracleithrum fixes on the cleithrum with a help of a ligament. The scapula and coracoid are not separated and create a scapulocoracoid. Yet, we did not observe the coracoid canal that is present in some sturgeon species [14]. American paddlefish also has the clavicle which is attached to the cleithrum and scapulocoracoid. However, there is no interclavicle. The mesocoracoid has a form of an arch. On its posterior margin the mesocoracoid has fossae for receiving the two radials and protuberances for the articulation with the propterygium and metapterygium, respectively. Other three radials are not in contact with the endoskeletal pectoral girdle, and decrease in length posteriorly along the metapterygium. Unlike in Russian sturgeon, the distal radials of triangular shape are wedged between the proximal radials. The mesocoracoid is also pierced in the middle by the foramen for the nerves and vessels of the pectoral fin.

The adductor and abductor of the pectoral fin are divided into two parts - superficial and profundus. Both parts end on the lepidotrichia of the pectoral fin. The marginal ray retains its individuality and the marginal muscles are also well developed. Together with the main muscle portion, they effect a flexible movement of the fin.

\section{DISCUSSION}

American paddlefish is a basal ray-finned fish that has a pectoral fin morphology resembling that of primitive bony fishes, ancestral to the tetrapod lineage [19]. Likewise, previous investigations showed that the fins of paddlefish exhibit pattern 
of expression of Hox genes that had been previously considered to be present only in developing limbs of tetrapods [7]. Moreover, paddlefish are close relatives of the sturgeons [13]. According to the analysis of the combined gene sequences, it was suggested that paddlefish even occupies a basal placement in regard to sturgeons [16]. It was confirmed that the early development in American paddlefish is very similar to that reported for sturgeons $[4,8]$.

Thus, it is not surprising that the structure of the pectoral girdle in American paddlefish has characteristics common to sturgeons. The pectoral fin web of Russian sturgeon, as well as in all sturgeons, is oriented horizontally, while in American paddlefish - dorso-laterally and generally horizontally during swimming [22]. The supracleithrum of polyodontids and acipenserids carries a sensory canal that runs from the posttemporal bone to the trunk lateral line $[9,18]$. A conjecture was made, that a special relationship between the posttemporal and endocranium involved the exclusion of the lateral extrascapular in sturgeons [15]. The scapulocoracoid cartilage in American paddlefish and Russian sturgeon has no clear division into scapula and coracoid. Moreover, its structure is variable among sturgeons [9]. Altogether with mesocoracoid, metapterygium, radials and propterygium, the scapulocoracoid cartilage may ossify in large specimens of fish $[9,18]$. The upper and lower muscle canals enclose the musculature of the pectoral fin in both species. The presence of the propterygial canal for marginal nerves and vessels, as well as the position of radials in two series, proximal and distal, seem to be the distinctive features for Acipenseriformes.

Nonetheless, the shoulder girdle of Acipenser and Polyodon differs in several ways. In Russian sturgeon, the clavicle and cleithrum are strongly developed in comparison with American paddlefish. Another dissimilarity between Russian sturgeon and American paddlefish is the quantity of proximal radials. The number of proximal radials is variable among species and even between individuals [9]. However, in the examined specimens of Russian sturgeon we counted 3 proximal radials (i.e., supported directly by the scapulocoracoid cartilage or, if we consider scapula and coracoid as separate structures, by the mesocoracoid) and 2 premetapterygial proximal radials. In the examined specimens of American paddlefish we found 2 and 3 proximal radials, respectively. In addition, the muscles which act on the pectoral fin of the investigated species have topographical similarity, but different extent of development. Dorsal muscles are more developed in Russian sturgeon and ventral muscles - in American paddlefish. We believe this is due to the fact that Russian sturgeon is a bottom-dwelling fish [5], whose pectoral fins are placed strictly horizontally to the substrate and less motile than the pectoral fins in American paddlefish. Therefore, the compensation for the breadth of the fin articulation and stabilisation of the body during swimming differs.

\section{CONCLUSIONS}

The anatomical structure of the pectoral girdle and the pectoral fin, documented in this study, provides an outline of characteristics that ultimately should be applicable in hypothesising relationships among the Acipenseriformes. Indeed, all the described herein morphological features of Russian sturgeon and American paddlefish show that their pectoral girdle appears to be a distinctive type, as compared with that of other ray-finned fishes. The similarities and differences between these phylogenetically informative taxa should be investigated further, to determine the evolutionary levels which are occupied by Polyodontidae and Acipenseridae as the unique representatives of the living fossils.

\section{REFERENCES}

1. Artyukhin EN, Vecsei P, Peterson DL (2007) Morphology and ecology of Pacific sturgeons. Environ Biol Fishes, 79: 369-381.

2. Bakhshalizadeh S, Bani A, Abdolmalaki S (2013) Comparative morphology of the pectoral fin spine of the Persian sturgeon Acipenser persicus, the Russian sturgeon Acipenser gueldenstaedtii, and the Starry sturgeon Acipenser stellatus in Iranian waters of the Caspian Sea. Acta Zool, 94: 471-477.

3. Bemis WE, Findeis EK, Grande L (1997) An overview of Acipenseriformes. In: Birstein VJ, Waldman JR, Bemis WE eds. Sturgeon Biodiversity and Conservation. Dev Environ Biol Fishes, 17: 25-71.

4. Bemis WE, Grande L (2005) Early development of the actinopterygian head. I. External development and staging of the paddlefish Polyodon spathula. J Morphol, 213: 47-83.

5. Billard R, Lecointre G (2001) Biology and conservation of sturgeon and paddlefish. Rev Fish Biol Fisher, 10: 355-392.

6. Boisvert CA (2005) The pelvic fin and girdle of Panderichthys and the origin of tetrapod locomotion. Nature, 438: 1145-1147.

7. Davis MC, Dahn RD, Shubin NH (2007) An autopodial-like pattern of Hox expression in the fins of a basal actinopterygian fish. Nature, 447: 473-476. 
8. Davis MC, Shubin NH, Force A (2004) Pectoral fin and girdle development in the basal actinopterygians Polyodon spathula and Acipenser transmontanus. J Morphol, 262: 608-628.

9. Dillman CB, Hilton EJ (2015) Anatomy and early development of the pectoral girdle, fin, and fin spine of sturgeons (Actinopterygii: Acipenseridae). J Morphol, 276: 241-260.

10. Findeis EK (1997) Osteology and phylogenetic interrelationships of sturgeons (Acipenseridae). Environ Biol Fishes, 48: 73-126.

11. Grande L, Bemis WE (1996) Interrelationships of Acipenseriformes, with Comments on Chondrostei. In: Stiassny MJ, Parenti LR, Johnson GD eds. Interrelationships of fishes. Academic Press, San Diego, pp. 85-115.

12. Hurtovoj NN, Matveev BS, Dzerzhinskii FY (1976) Practical zootomy of vertebrates. Lower Chordates, Agnatha, Pisces. Vysshaja Shkola, Moscow (in Russian).

13. Jennings CA, Zigler SJ (2000) Ecology and biology of paddlefish in North America: historical perspectives, management approaches, and research priorities. Rev Fish Biol Fisher, 10: 167-181.

14. Jessen HL (1972) Schultergurtel und Pectoralflosse bei Actinopterygiern. Fossils Strata, 1: 1-101.

15. Jollie M (1980) Development of head and pectoral girdle skeleton and scales in Acipenser. Copeia, 2: 226-249.
16. Krieger J, Fuerst PA, Cavender TM (2000) Phylogenetic relationships of the North American Sturgeons (order Acipenseriformes) based on mitochondrial DNA sequences. Mol Phylogenet Evol, 16: 64-72.

17. Mabee PM (2000) Developmental data and phylogenetic systematics: evolution of the vertebrate limb. Am Zool, 40: 789-800.

18. Mabee PM, Noordsy M (2004) Development of the paired fins in the paddlefish, Polyodon spathula. J Morphol, 261: 334-344.

19. Metscher BD, Takahashi K, Crow K, Amemiya C, Nonaka DF, Wagner GP (2005) Expression of Hoxa-11 and Hoxa-13 in the pectoral fin of a basal ray-finned fish, Polyodon spathula: implications for the origin of tetrapod limbs. Evol Dev, 7: 186-195.

20. Yano T, Tamura K (2013) The making of differences between fins and limbs. J Anat, 222: 100-113.

21. Wagner GP, Chiu C-H (2001) The tetrapod limb: a hypothesis of its origin. J Exp Zool (Molecular Development and Evolution), 291: 226-240.

22. Wilga CD, Lauder GV (1999) Locomotion in sturgeon: function of the pectoral fins. J Exp Biol, 202: 2413-2432.

23. Zhu M, Yu X (2009) Stem sarcopterygians have primitive polybasal fin articulation. Biol Lett, 5: 372-375. 